\title{
El portafolio digital ¿Una herramienta para aprender a ser docentes críticos?: Un estudio de casos
}

The digital portfolio. A tool to learn to be critical teachers? A case study

\author{
Volumen 19, Número 3 \\ Setiembre-Diciembre \\ pp. 1-32
}

\section{Laura de la Concepción Muñoz González Encarnación Soto Gómez}

\section{Citar este documento según modelo APA}

Muñoz González, Laura de la Concepción y Soto Gómez, Encarnación. (2019). El portafolio digital ¿Una herramienta para aprender a ser docentes críticos?: Un estudio de casos. Revista Actualidades Investigativas en Educación, 19(3), 1-32. Doi. 10.15517/aie.v19i3.38632 


\title{
El portafolio digital ¿Una herramienta para aprender a ser docentes críticos?: Un estudio de casos
}

\author{
The digital portfolio. A tool to learn to be critical teachers? A case study
}

\section{Laura de la Concepción Muñoz González ${ }^{1}$ Encarnación Soto Gómez²}

\begin{abstract}
Resumen: La finalidad de este artículo es compartir las oportunidades pedagógicas del portafolio digital como recurso de enseñanza, aprendizaje y evaluación durante la formación inicial docente, especialmente en lo que respecta al desarrollo de competencias para afrontar los retos educativos del siglo XXI. Se realizó un estudio de casos (2015-2019) focalizado en un grupo de 60 estudiantes de Educación Infantil de la Universidad de Málaga (España) y 4 docentes, mediante un diseño mixto para la recolección de la información. En este sentido, el análisis cualitativo y cuantitativo, la saturación y la triangulación de los datos recogidos a través de observaciones, entrevistas, cuestionarios cerrados y abiertos, así como grupos focales determinaron categorías iniciales y finales. Como resultados, se encontró, en primer lugar, que el portafolio digital es una herramienta que contribuye con clarificar la necesidad de establecer una definición compartida para su uso y, en segundo lugar, reconoce su potencialidad para promover la conciencia y construcción del propio conocimiento, la reconstrucción del pensamiento práctico, el desarrollo de competencias profesionales docentes y la evaluación integral. El alcance de esta investigación puede ayudar a promover el estudio de buenas prácticas de evaluación en la universidad, la necesaria actualización tecnológica, así como la aplicación de estrategias metodológicas que favorezcan el desarrollo de competencias docentes adaptadas a la sociedad de la información y el conocimiento.
\end{abstract}

Palabras clave: formación inicial docente, portafolio digital, competencias docentes, TIC

\begin{abstract}
The purpose of this article is to share the pedagogical opportunities of the digital portfolio as a resource for teaching, learning and assessment during initial teacher training, especially in terms of developing skills to meet the educational challenges of the 21st century. A case study (2015-2019) focused on a group of 60 Early Childhood Education students from the University of Malaga (Spain) and 4 teachers, through a mixed design for the collection of information. In this sense, qualitative and quantitative analysis, saturation and triangulation of the data collected through observations, interviews, closed and open questionnaires, as well as focus groups determined initial and final categories. As results, it was found, firstly, that the digital portfolio is a tool that contributes to clarifying the need to establish a shared definition for its use and, secondly, recognizes its potential to promote awareness and construction of one's own knowledge, the reconstruction of practical thinking, the development of professional teaching skills and integral evaluation. The scope of this research can help to promote the study of good evaluation practices in the university, the necessary technological updating, as well as the application of methodological strategies that favor the development of teaching skills adapted to the information and knowledge society.
\end{abstract}

Keywords: initial training teacher, digital portfolio, teacher qualifications, ICT

\footnotetext{
${ }^{1}$ Docente de la Universidad de Málaga, España. Dirección electrónica: lauramglez@uma.es ORCID https://orcid.org/0000-0003-1073-9098

2 Docente de la Universidad de Málaga, España. Dirección electrónica: esoto@uma.es
}

Artículo recibido: 18 de marzo, 2019

Enviado a corrección: 22 de mayo, 2019

Aprobado: 15 de julio, 2019 


\section{Introducción}

Cuando a finales de 1970 aparecieron las computadoras de 8 bits, las primeras en ser ampliamente utilizadas por los aficionados, nadie podía predecir los cambios sociales que su incorporación, así como su inminente evolución, supondrían a corto y largo plazo. Nacían los primeros ordenadores destinados al uso personal, el posterior acceso a internet y la silenciosa revolución tecnológica. Casi medio siglo después, resulta difícil concebir la vida sin estos procesadores electrónicos, ahora mejorados y disponibles en multiplicidad de formatos (tabletas, móviles, ordenadores fijos, portátiles, etc.). Nos encontramos en la era de la información, la era del conocimiento, un momento "de cambio vertiginoso, incremento de la interdependencia y de la complejidad sin precedentes, que está provocando una alteración radical en la atmósfera simbólica que respiramos, en nuestra forma de comunicarnos, actuar, pensar y expresar" (Pérez Gómez, 2017, p. 27). Pero ¿Cómo están influyendo estas transformaciones en el ámbito educativo? ¿Qué medidas se están llevando a cabo en la formación de las futuras personas docentes?

En el curso 2010-2011 dos profesoras del Departamento de Didáctica y Organización Escolar de la Universidad de Málaga, conscientes de las nuevas necesidades pedagógicas, aprovecharon las transformaciones impulsadas por el Espacio Europeo de Educación Superior (EEES) para poner en marcha un proyecto innovador de carácter interdisciplinar en la formación inicial de maestros y maestras del Grado de Educación Infantil, promoviendo la incorporación del portafolio digital Mahara en la Plataforma Virtual de Enseñanza de la Universidad (Moodle), al que denominaron Portafolio UMA.

Ocho años después de su introducción, y como consecuencia de los buenos resultados obtenidos, esta herramienta continúa siendo el eje principal del aprendizaje y la evaluación de las asignaturas impartidas por estas profesionales y ha llegado a formar parte, incluso, de muchas otras disciplinas del centro.

Con el fin de conocer esta experiencia y comprender en qué medida la herramienta puede favorecer el desarrollo de las competencias docentes, durante el curso 2015-2016, se puso en marcha un proyecto de investigación mixto financiado por el Ministerio de Ciencia, Innovación y Universidades de España, a través de la Beca de Formación del Profesorado Universitario (FPU) que se extendería hasta el curso 2018-2019.

A través de un minucioso análisis teórico sobre los nuevos retos y necesidades educativas, este artículo recoge los resultados de tres años de estudio, los cuales pueden 
ayudarnos a comprender en qué medida el portafolio digital Mahara puede favorecer el desarrollo de las competencias docentes del siglo XXI durante la formación inicial.

\section{Referente teórico}

\subsection{Aproximación a los nuevos retos de la sociedad del siglo XXI}

Transitamos una época incierta, con grandes descubrimientos y revoluciones, una época en la que la ciudadanía debe hacer frente a complejos retos científicos, demográficos, económicos, culturales, laborales, tecnológicos y políticos que, de un modo u otro, transforman nuestra manera de ser y estar en el mundo:

- La falta de certezas: Habitamos una era en el que la vida parece reinventarse sin cesar. Lo que hoy es útil, válido y aprovechable, mañana podría considerarse un elemento superfluo, inacabado e incluso inconveniente. Bauman (2004) describió nuestra época como modernidad líquida, una alegoría del cambio y la transitoriedad, donde la perdurabilidad ha dado paso a lo informe y voluble: "los fluidos, a diferencia de los sólidos, no conservan su forma durante mucho tiempo y están constantemente dispuestos a cambiarla" (p. 8.). Vivimos en el mundo de lo fugaz y de lo efímero, de una incertidumbre en la que todo y en especial, el conocimiento, parece desechable y cuestionable (Daza, 2010). La ausencia de certezas absolutas, la relatividad y el cambio vertiginoso del conocimiento confluyen en nuestra manera de mirar e interpretar la realidad. Asistimos a un mundo volátil, en el que las estructuras cambian con presteza antes de cristalizarse o ser capaces de garantizar alguna confianza (Bauman, 2007). Un mundo que, como expresa Armitage (2001, p. 40) "ya no tiene ningún tipo de estabilidad, está todo el tiempo deslizándose y escurriéndose silenciosamente".

- La sobrecarga informativa: En la era de la información digitalizada, el acceso al conocimiento parece relativamente sencillo e inmediato, sin embargo, conseguir datos veraces, objetivos y fiables, no está exento de dificultades. Actualmente, existen alrededor de 4.4 billones de páginas webs (De Kunder, 2018) y una cantidad de contenidos que solo puede ser medido en términos de zettabytes. La Tecnología de la Información y Comunicación ha permitido que los usuarios se transformen en auténticos prosumidores, o lo que es lo mismo, productores y consumidores simultáneos de información. Como explica García-Galera y Valdivia (2014, p. 10) "frente al papel tradicional de la audiencia como sujeto pasivo [...] los medios digitales 
han permitido que el receptor ocupe con frecuencia el lugar del emisor -capaz de generar contenidos y compartirlos“. Lyman et al. (2003) ya señalaron que entre 1999 y 2002 se creó más información que en toda la historia de la humanidad y estos datos masivos a gran escala o big data continúan creciendo, aproximadamente un $30 \%$ al año. Es lo que se denomina infoxicación, un término introducido por Cornellá (2004) para definir el crecimiento exponencial y abierto de información que intoxica y confunde a los ciudadanos. Niño González, Barquero Cabrero \& García García (2017) lo expresan del siguiente modo: "el público general pueda producir su propio contenido informativo con los mismos déficits de objetividad con que los consume [...] es editor de su propia información y de su propia desinformación". Si a esto le sumamos los algoritmos de búsqueda personalizadas, las cámaras de eco o las burbujas de filtro, "entendidas como mecanismos que establecen la dieta informativa diaria de cada usuario a modo de iterativos microclimas de opinión y burbujas ideológicas" (Rodríguez Cano, 2017, p. 64), resulta urgente el desarrollo de competencias humanas reflexivas y críticas que promuevan la capacidad de un filtrado con sentido y significado de la información (Pinto Santos, Díaz Carreño y Santos Pinto, 2018, p. 108).

- El hiperconsumismo e individualidad: En un mundo globalizado e interconectado como el nuestro, donde conviven culturas, deseos e intereses y se demanda, sin descanso recursos, concepciones, ideas, símbolos e imágenes diferentes, se ha producido un seísmo que ha revolucionado el capitalismo tal y como lo conocíamos, dando lugar a: la sociedad del hiperconsumo "insaciable pero también indisociable del consumo [...] en la que nunca puede satisfacer sus apetitos, pero tampoco puede llegar a un estado de saturación" (Moret, 2012, p. 344). La vía de fabricación fordiana de producción de bienes estandarizados se ha transformado en una economía de lo variado, donde la innovación y renovación productiva son los nuevos estándares de competitividad empresarial. "Nace un Homo consumericus de tercer tipo, una especie de turboconsumidor desatado, móvil y flexible, liberado en buena medida de las antiguas culturas de clase, con gustos y adquisiciones imprevisibles" (Lipovetsky, 2007, p. 10).

Es decir, surge, un consumidor global en un mercado sin fronteras y accesible que, a la vez, convive con la promoción de lo individual, de la diferencia, de la libertad de elegir en todo momento. Singly (2003) nos habla de la "despertenencia", conducta en la que los sujetos rompen con las ataduras de lo recibido congénitamente para escoger otras cosas nuevas, que de ser lo mismo, resultaría una elección personal. Esta búsqueda 
de individualidad, de conocimiento y construcción perpetua de uno mismo ha sido sagazmente aprovechada por el mercado. Casi cualquier establecimiento ofrece, hoy, bienes y servicios que buscan favorecer la individualidad, el desarrollo personal, la indagación interior, el confort psíquico o esa plenitud subjetiva derivada de las doctrinas orientales. "El materialismo de la primera sociedad de consumo ha pasado de moda: actualmente asistimos a la expansión del mercado del alma y su transformación, del equilibrio y la autoestima, mientras proliferan las farmacopeas de la felicidad" (Lipovetsky, 2007, p. 10). Se vincula el consumo con el estilo de vida y se transforma el tener en una oportunidad para comunicar quién se es y promocionarse a sí mismo (Buxarrais, 2003).

- La hiperproductividad como fin último: Cualquier producto, desde el más simple al más sofisticado, es el resultado de la actividad humana en interacción con los medios tecnológicos para su producción, pues como indica Martínez (1997) "esta sigue siendo una sociedad que produce mercancías, que genera excedentes en el proceso productivo a partir de la interacción del hombre y la naturaleza”. Tal es así, que a diferencia de lo que antaño se presuponía cuando las máquinas comenzaron a sustituir las ocupaciones humanas, nos encontramos con una población sobreocupada, sometida a labores mediadas por la competitividad, de difícil desconexión y a un tiempo de ocio de cuestionable calidad. Como señala Pinilla (2017, p. 22) "El programa neoliberal y su legitimación en las últimas décadas promueve una ideología que exalta al individuo-empresa y la eficiencia creativa como paradigma". Esta ética liberal ha llevado a la consolidación de individuos autodisciplinados, multitareas, de los que se requiere un continuo reciclaje.

Del mismo modo "el paradigma de la competitividad ha permeado todos los espacios del desarrollo [...] y se presenta como la opción ideal para el progreso y modernización, tanto de las organizaciones como de las naciones" (Valdez Zepeda, 2008). Sin embargo, este capitalismo de crecimiento, obsesionado con ofrecer siempre mayores resultados en un menor tiempo y con la mínima inversión posible, no solo implica la contaminación irrefrenable del medio ambiente, sino un progresivo agotamiento de los recursos no renovables. Goñi Zubieta (2010, p. 28) culpabiliza de ello a la ética borrosa de una sociedad carente de criterios morales que se ve necesariamente abocada a estar hiperreglada, obligada a ir desgranando leyes cada vez más concretas que regulen todos los aspectos de la vida de los ciudadanos, ya 
que muy pocos parecen querer asumir su responsabilidad individual ante sus propias actuaciones, a pesar de que beneficien a pocos y perjudiquen a muchos, como todos aquellos hábitos o estilos de vida que provocan contaminación ambiental. En este sentido, Uprimny (2017) propone un modelo económico de la pereza o la racionalidad del ocio, defendiendo la posibilidad de crear felicidad para todo el mundo con menos opulencia, es decir, vivir mejor produciendo y consumiendo menos, con la consiguiente extensión del tiempo libre.

- El síndrome de la impaciencia (Bauman, 2007): En un mundo saturado de estímulos, acostumbrado a la velocidad de las nuevas tecnologías para lograr nuestros objetivos y sujeto a la prolongación difusa de los horarios de trabajos-multitarea, sostener la espera resulta cada vez más engorroso. Así es como las "labores que solían efectuarse diariamente, en general sin quejas y a menudo con placer, han llegado a considerarse como una pérdida desechable, aborrecible y detestable de tiempo y energía”, e incluso, en un estigma social de inferioridad (Bauman, 2007, p. 19). Cubertería de usar y tirar que evita el posterior enjuague, sopas instantáneas para consumir en pocos minutos o frutas sin cascara dentro de contenedores plásticos, aumentan su presencia en los supermercados. Una circunstancia que Shi (1985) bautizó como "síndrome de la aceleración", donde la espera se experimenta como una coyuntura intolerable. Esta falta de sosiego, junto al creciente temor por la desocupación rentable, están disminuyendo la calidad de vida de la población y, como señala Pinilla (2017), aumentando el número de "sujetos deprimidos, agotados, exhaustos, que la sociedad reconduce con mayor o menor fortuna mediante la proliferación de terapias o la medicalización creciente de la población”.

Estamos inmersos en un modelo donde se estimula la actividad constante sin tiempo para la reflexión, el recogimiento o el juicio razonado, donde se premia a los activos y se castiga a los pasivos, convirtiendo el estrés y la depresión en las enfermedades psicológicas del momento (Goñi Zubieta, 2010, p. 25). No obstante, y en contraposición, hoy también nos encontramos con un aumento de los "discursos críticos y formas de disidencia que proponen desactivar el prestigio de la acción, cuestionando cualquier exceso productivista mediante el potencial antisistémico del cansancio, del sueño, de la lentitud" (Pinilla, 2017, p. 5).

- La nueva identidad digital: El auge de las redes e interconexiones ha permitido favorecer el acercamiento entre los diferentes agentes sociales. Sin un lugar físico en 
el que interactuar, la acción de los actores se descontextualiza, ampliando el rango de alcance y la creación de un nuevo marco histórico global en el que se produce y reproduce la experiencia social. Antes de que apareciese internet, la identidad de una persona estaba supeditada a la documentación oficial escrita, generada en los establecimientos destinados para ello; en cambio, hoy, la posibilidad de manifestarnos a través de diferentes dispositivos, aplicaciones y entornos digitales, ha favorecido la creación de la identidad digital, que según Giones Valls y Serrat Brustenga (2010) puede ser una o múltiples. Si tenemos en cuenta que esta nueva careta humana -a veces proyectada por avatares- nace y se desarrolla al tiempo que experimentamos un cambio en la cultura global, podemos hacernos una idea de la complejidad de la situación y los riesgos que entraña. Por un lado, la posibilidad de configurar una identidad digital revestida de aparente anonimato nos invita a creer decidir, en todo momento, lo que queremos revelar. Sin embargo, como señala Turkle (2015) los límites que separan la verdadera identidad de la digital se vuelven borrosos y puede ser difícil mantenerlos rectos.

Es decir, tanto la participación negativa (insultos, violencia...) como el despliegue de cualidades o vidas perfectas construyen esa "máscara virtual del yo real que deja las huellas de lo que dice ser en los distintos entornos virtuales en donde interactúa" (Rivera Piragauta y Minelli de Oliveira, 2017) lo que permite determinar el tiempo pasado en redes, las webs a las que se accede, la simpatía con ciertos sectores, la participación en debates, gustos, viajes y una serie de información que exponen la privacidad del individuo. Por otro lado, actualmente, existen conflictos en la regulación de elementos como la libertad de información y la protección de datos personales, la libertad de expresión, la censura y el derecho al olvido (Manzanero Jiménez y Pérez García-Ferreira, 2015) que aún no se encuentran claramente reglamentados.

No nos gustaría concluir el apartado sin advertir que estos retos constituyen, tan solo, una pequeña muestra de los desafíos a los que las sociedades del siglo XXI deben enfrentarse. De ningún modo desestimamos otros factores y lejos de considerar la modernidad como un concepto omniabarcable, acogemos el concepto de modernidades múltiples introducido por Beriain (2005), según el cual, la sociedad mundial actual se desarrolla y transita por diversos caminos de la modernidad, desde perspectivas políticas, sociales, tecnológicas y culturales diferentes. 


\subsection{Hacia un sistema educativo conectado y comprometido con el desarrollo de las competencias fundamentales}

Como refleja el apartado anterior, vivimos inmersos en contextos supercomplejos, fundamentalmente urbanos, interconectados, acelerados, sobrestimulados, saturados de información, con propósitos imprevisibles, cambiantes, frágiles o desdibujados, en los que se celebra la heterogeneidad e individualidad, al mismo tiempo que se auspicia el anonimato.

No obstante, y a pesar de la evidente y apremiante necesidad de cambio, la mayor parte de las escuelas continúan aferradas a viejas estructuras metodológicas que preparan poco o nada para los nuevos retos a los que nos enfrentamos. Escuelas que continúan promoviendo la uniformidad, la excesiva producción de tareas descontextualizadas, la obediencia sumisa, el aprendizaje fragmentado, homogéneo y eurocéntrico. Escuelas en las que se valora lo teórico y memorístico por encima de la experiencia directa y significativa, la creatividad o la iniciativa personal. Se trata de una pedagogía heredada de la época industrial, donde la transmisión era unidireccional y abstracta, la organización del espacio y el tiempo homogéneos y rígidos, los estándares de aprendizaje comunes, la evaluación estándar y el currículum educativo estaba comprimido. Es decir, un sistema en el que las disciplinas y elementos que las conformaban fueron fragmentadas, al igual que lo eran los trabajos en las fábricas.

Sin embargo, ya no podemos continuar confundiendo la adquisición de conocimientos con la mera memorización de datos, sobre todo después de que las nuevas tecnologías nos permitan acceder instantáneamente a cualquier información que deseemos conocer. El futuro de la educación parece situarse en la necesidad de ayudar a las personas a reflexionar, desarrollar el espíritu crítico, seleccionar información de calidad, contrastarla, interpretarla y organizarla de manera lógica y útil. O sea, darle herramientas para que sean capaces de navegar en la incertidumbre, ser creativas, construir sus propias ideas y mapas mentales, comprender la complejidad política, económica y cultural existente, desarrollar empleos desconocidos hasta ahora, diseñar y utilizar técnicas todavía no inventadas y en definitiva intervenir de la mejor manera posible en una realidad incierta.

Pérez Gómez (2012, p. 29) resume del siguiente modo, las competencias fundamentales que deberían desarrollarse dentro de las escuelas para el buen desenvolvimiento de las personas ciudadanas en el actual escenario contemporáneo:

- Capacidad de utilizar y comunicar de manera disciplinada, crítica y creativa las herramientas simbólicas que ha elaborado la humanidad a lo largo de su historia. Esto 
es, aprender a observar, indagar, contrastar, experimentar, argumentar, decidir y actuar.

- Capacidad para afrontar los inevitables conflictos sociales de forma pacífica mediante el diálogo, el consenso y el debate democrático, con actitud de respeto, escucha y colaboración, así como aprender a vivir y convivir en grupos humanos social y culturalmente heterogéneos.

- Capacidad para desarrollarse de manera autónoma, aprender a aprender, adquirir criterios personales, gobernar el propio y singular proyecto vital en sus tres dimensiones: personal, social y profesional. Conocerse y comprender la complejidad de las dimensiones explícitas y tácitas, cognitivas, emocionales y comportamentales que constituyen la propia identidad.

Así pues, hoy, más que nunca, los centros educativos que creen firmemente en la función que tienen encomendada se ven obligados a ir contracorriente, a ofrecer al alumnado oportunidades que le permitan desarrollar las competencias que necesitan para comprender, adaptarse y desenvolverse en el momento histórico que les ha tocado vivir.

\subsection{La formación inicial docente: Eje del cambio educativo}

La apremiante necesidad de un cambio en el sistema educativo debe comportar, a su vez, una profunda reflexión y replanteamiento del modelo de formación inicial del profesorado porque "no es posible cambiar la educación sin modificar las actitudes, la mentalidad y la manera de ejercer la profesión; y esto es solo posible si actuamos desde la formación inicial” (Imbernón Muñoz, 2017, p. 58). En este sentido, hay que tener en cuenta que el alumnado que aspira a la docencia cuenta con un amplio recorrido académico saturado de convicciones y creencias acerca de lo que es enseñar, lo que significa aprender y cómo se debe evaluar. Sus recuerdos se encuentran estrechamente ligados a la metodología tradicional, caracterizada por las clases magistrales, el rol pasivo de los aprendices, la memorización y los exámenes como herramienta evaluadora. Resulta inevitable que estas concepciones formen parte de su conocimiento práctico, es decir, sus automatismos funcionales e inconsciente, producto de la sucesión de errores pedagógicos vivenciados (Pozo Municio, 2014).

Asimismo, dichas construcciones se encuentren acompañadas de carencias en ciertas competencias, pues, como indica López Escudero (2002), “Los estudiantes aprenden a 
subrayar, a hacer esquemas o mapas conceptuales, pero luego son incapaces de trasladar estas estrategias de aprendizaje a las diferentes áreas curriculares o de hacer un uso reflexivo de las distintas técnicas que han adquirido". A este respecto, el documento Bolonia de 1999 y las propuestas del Espacio Europeo de Educación Superior (EEES) fueron claves para iniciar en España la transformación de una vida académica universitaria, caracterizada por su rigidez y uniformidad, hacia una concepción de la enseñanza más abierta y flexible, centrada en el aprendizaje. No obstante, nuestro sistema educativo permanece, "salvo dignas excepciones, claramente estancado en un modelo obsoleto de enseñanza como transmisión oral de información en clases masificadas, toma de apuntes y reproducción de contenidos aprendidos de memoria para responder a exámenes y pruebas estandarizadas de papel y lápiz" (Pérez Gómez, 2016, p.7). De alguna manera, "los cambios se convierten, en el mejor de los casos, en meras reformas burocráticas y rituales que modifican la superficie de los procesos sin afectar realmente el núcleo de las prácticas" (Junta de Andalucía, 2009, p. 7) si no son comprendidos ni aceptados por quienes tienen el deber de aplicarlos.

Así pues, parece fundamental trasladar estos nuevos principios y metodologías a la formación inicial del profesorado, con el fin de preparar docentes críticos, capaces de analizar, cuestionar, evaluar y transformar su propia práctica, aumentando su conciencia sobre los contextos en los que trabajan, valorando asuntos morales y éticos implícitos en su práctica, así como fortalecer el control sobre su crecimiento profesional, influyendo en las direcciones futuras de la educación (Calderhead y Shorrock, 1997). Para llevar a cabo todas estas funciones, tan ricas como complejas, el profesorado debe desarrollar una serie de competencias docentes, un tema objeto de debate y valoraciones dispares. Pérez Gómez (2012, p. 249) las resume en las siguientes:

- Competencia para planificar, desarrollar y evaluar la enseñanza que pretende fomentar el desarrollo de las cualidades humanas deseables en el estudiantado.

- Competencia para crear y mantener contextos de aprendizaje abiertos, flexibles, democráticos y ricos culturalmente, donde se estimule un clima positivo de aprendizaje.

- Competencia para promover el propio desarrollo profesional y la formación de comunidades de aprendizaje con el profesorado y resto de los agentes implicados en la educación. 


\subsection{El Portafolio Digital Mahara, una herramienta educativa que se adaptada a las necesidades formativas actuales}

La incorporación al EEES y la búsqueda de nuevas formas de acercar el aprendizaje al alumnado han favorecido la aparición de nuevas estrategias metodológicas de aprendizaje y evaluación que promueven la acción creativa y crítica del estudiantado en contextos complejos, más allá de la mera reproducción de saberes. Entre estas herramientas destaca el portafolio educativo, un recurso que, como diferentes investigaciones apuntan, parece facilitar el desarrollo autónomo, interactivo y consciente de las competencias mencionadas (Barragán Sánchez, 2005; Castro Quitora, 2006 y Klenowski, 2014).

La extensa literatura existente sobre la herramienta impide establecer una definición única que contemple el total de sus atributos, pero teniendo en cuenta distintas autorías como Danielson y Abrunty (1999), Lyons (2003), Cano (2005), Martínez (2009) o Pérez (2016), podríamos resumir las características del portafolio educativo en las siguientes:

- No es una mera "caja llena de cosas". Tampoco se trata de un dossier en el que se introducen todos los trabajos elaborados a lo largo del año, seguidos de una reflexión superficial.

- Es un documento personal que incluye una colección deliberada de tareas significativas, acompañadas de reflexiones bien elaboradas que permitan registrar la trayectoria y evolución del aprendizaje.

- La narrativa constituye el elemento fundamental del portafolio y es a través de ella como se potencia la construcción y organización del conocimiento.

- Su elaboración promueve la reflexión, el pensamiento crítico, la metacognición y el conocimiento de uno mismo.

- Los autores y las autoras del portafolio participan en su propia evaluación y deben tener claro, desde el principio, sus fines, criterios y pautas de elaboración.

- El alumnado y su aprendizaje son los principales protagonistas del portafolio y cada portafolio es una creación única.

En definitiva, podemos describir el portafolio como aquella agrupación de evidencias sobre el propio desarrollo y aprendizaje que ayuda al estudiantado a recoger:

Las competencias que han logrado apropiar en un curso, los intereses emergentes de sus procesos de aprendizaje, las experiencias que ha tenido lugar en el transcurso del tiempo, la vinculación entre contenidos de orden teórico y aspectos de orden práctico, 
sus procesos de metacognición y sus criterios de valoración para seleccionar los trabajos que consideren más representativos de sus intereses, logros, motivaciones y aprendizajes. (Castro Quitora, 2006, p. 1)

No obstante, tal y como señalan Soto Gómez, Barquín Ruíz y Fernández Navas (2016), un portafolio educativo en el marco del contexto actual ha de ser digital porque favorece la flexibilidad, sincronía y pluralidad de códigos de comunicación. A este respecto, destacamos el portafolio digital Mahara (del Maorí: pensamiento), un software de código abierto, ganador del Premio Mellon en 2007, ampliamente utilizado en universidades de todo el mundo (Nueva Zelanda, Australia, Reino Unido, Canadá) y que poco a poco comienza a instaurarse en España. Se trata de una herramienta de enseñanza aprendizaje que actúa a la vez de portafolio y red social, ofreciendo la oportunidad de escribir diarios, adjuntar contenido electrónico (imágenes, vídeos, música, documentos), organizarlos de manera personalizada, enviar y recibir retroalimentación constante a través de la tutoría y entre iguales, así como construir un sistema de red capaz de conectar a las personas y crear comunidades en línea.

\section{Metodología}

\subsection{Enfoque}

A fin de profundizar en la comprensión de los fenómenos objeto de nuestro estudio, seguimos un enfoque de investigación mixto de alcance explicativo que se apoya en el método del estudio de casos o "estudio de la particularidad y de la complejidad de un caso singular para llegar a comprender su actividad en circunstancias importantes" (Stake, 2005, p. 11). Nuestro objetivo es conocer, comprender y describir, a través del análisis de una experiencia singular, las posibilidades y restricciones pedagógicas de la red social y portafolio digital Mahara, así como su papel en la formación inicial docente. Para ello, respetamos las etapas de investigación que se recogen en la Figura 1.

Las estrategias de recogida y análisis de información cualitativas empleadas fueron la observación directa de varias sesiones de clase, un cuestionario abierto inicial (Anexo 1), un cuestionario abierto final (Anexo 2), entrevistas individuales a las docentes (Anexo 3), entrevistas individuales al estudiantado (Anexo 4), grupos focales (Anexo 5) y análisis documental de portafolios, lo que favorece la producción de "hallazgos a los que no se puede llegar por medio de procedimientos estadísticos u otras formas de cuantificación" (Strauss y 
Corbin, 2002, p. 19), ya que son influidos por las diferencias contextuales y sus elementos sociales, tales como: las emociones, saberes, creencias, valores, habilidades y actitudes, lo que favorece la comprensión de los fenómenos sociales. No obstante, con el fin de recoger el universo de percepciones y vivencias del alumnado, nuestra investigación también incorporó un cuestionario cerrado (Anexo 6) como herramienta cuantitativa que abarca toda la muestra del alumnado, cuya triangulación con el resto de la información recogida nos permitió ampliar y profundizar en el entendimiento de los ejes de sentido detectados y la corroboración de información, así como orientar la explicación, la comprensión y la transformación de la experiencia (Creswell y Plano, 2011).

Figura 1

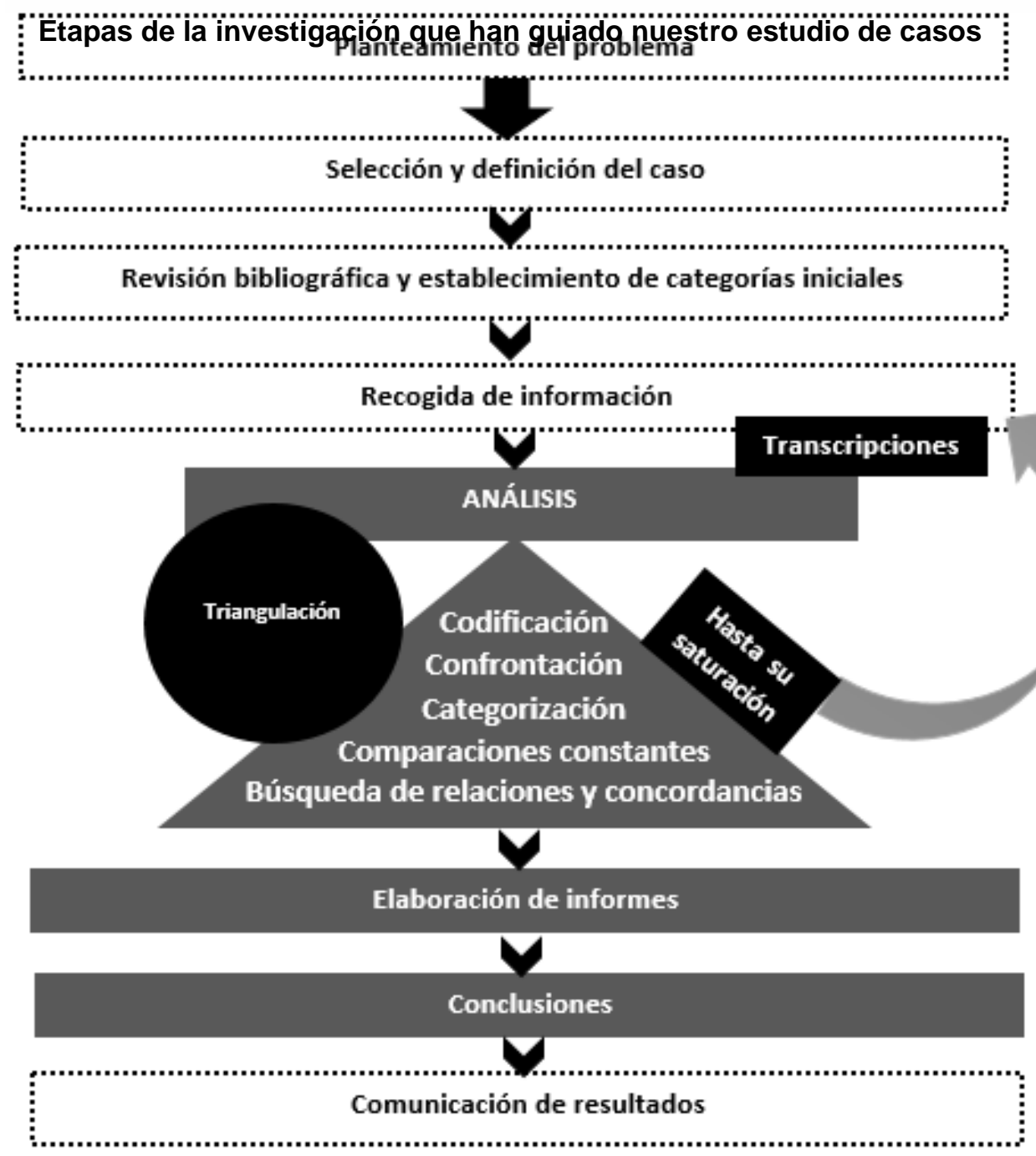

Fuente: elaboración propia, atendiendo a los procedimientos que debe seguir el estudio de casos según Robert E. Stake, 2005. 


\subsection{Población de estudio}

Esta investigación comenzó a desarrollarse en la Facultad de Ciencias de la Educación de la Universidad de Málaga durante el curso 2015-2016 (hasta 2018-2019), específicamente en un grupo de 60 estudiantes de primer año del grado de Educación Infantil, en la que cuatro docentes llevaban a cabo una propuesta metodológica que partía de unas cuidadas vivencias de aula que favorecían la revisión de conocimientos, creencias, actitudes, emociones y valores que el alumnado tenía asociados a la enseñanza y a su propio aprendizaje.

Figura 2

Uso de la herramienta Mahara en la experiencia investiaada

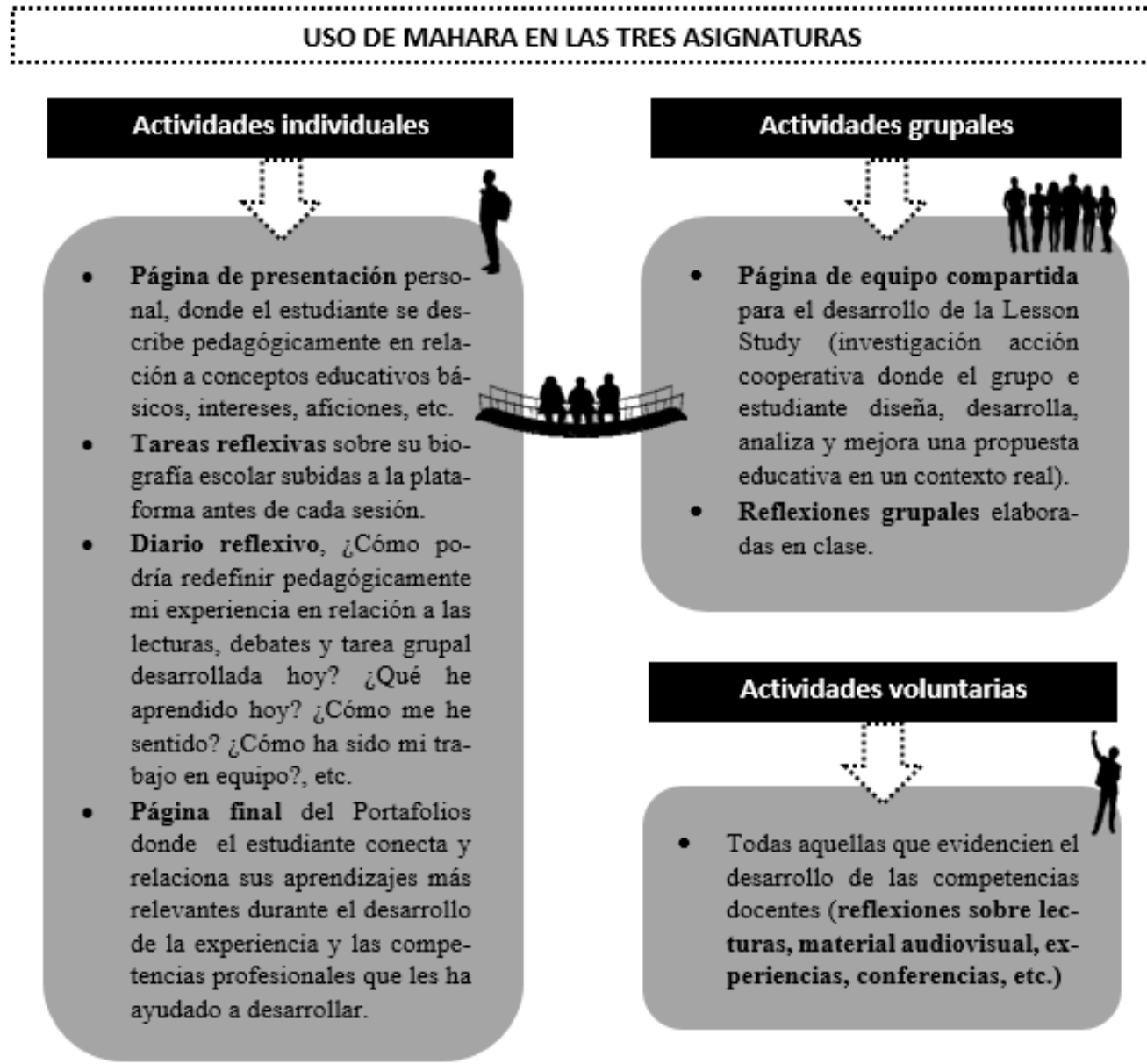

Fuente: elaboración propia a partir de los datos de la investigación, 2019.

Atendiendo a Giné Freixes (2009, p. 120), el alumnado universitario adquiere, construye y utiliza conocimientos sobre el proceso de enseñanza-aprendizaje del cual forma parte, por lo que resulta fundamental ofrecerle unas experiencias significativas En este 
sentido, la red social y portafolio digital Mahara, siendo trabajada de un modo semiestructurado (Figura 2), se constituyó como la piedra angular de todo el proceso formativo a través de tres asignaturas: Didáctica de la educación infantil, Organización de la escuela infantil y Hacia una escuela inclusiva, cuyo funcionamiento coordinado e interdisciplinar seguía una metodología en la que primaba el cuestionamiento y la reflexión desde el constructivismo: la Lesson Study y el Aprendizaje y Servicio. Gracias a esta herramienta y a las actividades que se promovían en ella se hizo posible dar autonomía y voz al alumnado, acompañarlo en la reflexión sobre sus experiencias y favorecer la relación con sus compañeros y compañeras (Soto Gómez, Serván Núñez y Caparrós Vida, 2016).

Tal y como se recoge en la Figura 3, la muestra del estudio de casos fue de 72 participantes, conformados por el grupo uno o total de estudiantes del aula en el que se desarrolla el estudio de casos (G1); el grupo dos o estudiantes específicos que continuaron utilizando la herramienta en años posteriores (G2: E1 y E2), donde E1 es estudiante uno y E2, estudiante dos; el grupo tres o las docentes protagonistas del estudio de casos (G3: D1...D4), donde D1 es docente uno, hasta docente cuatro; así como el grupo cuatro o estudiantes de distintas promociones que habían formado parte de la experiencia con anterioridad y continuaban utilizando el portafolio Mahara como herramienta de aprendizaje (G4: A1...A8), donde A1 es estudiante uno, así hasta estudiante ocho.

Figura 3

Número de participantes de la muestra de estudio del estudiantado y profesorado de la Universidad de Málaga-España, 2016-2018

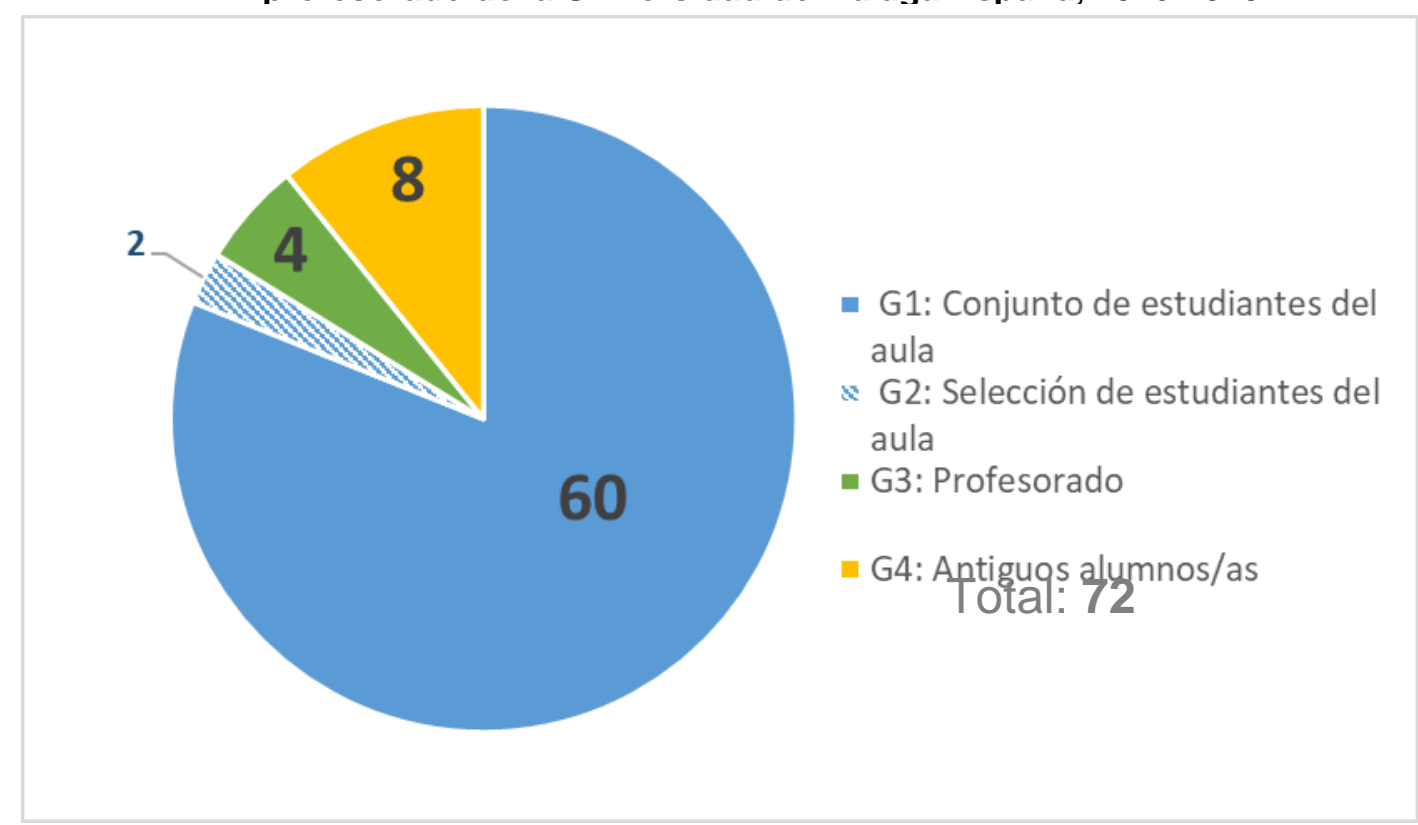

Fuente: elaboración propia a partir de los datos de la investigación, 2019. 
La muestra, previo consentimiento informado y compromiso de confidencialidad, fue seleccionada intencionalmente con el fin de conocer en profundidad una experiencia de enseñanza-aprendizaje significativa que girase en torno al uso del portafolio digital durante la formación inicial docente. El asesoramiento de las profesoras protagonistas del estudio de casos fue fundamental para escoger al alumnado específico de la muestra que participaba en la experiencia. Para ello, se respetaron los siguientes criterios de inclusión:

- G1: Pertenecer al grupo-clase en el que las docentes protagonistas del estudio de casos desarrollaron su proyecto interdisciplinar durante el curso 2015/2016.

- G2: Ser una persona estudiante perteneciente al grupo clase de $1^{\circ}$ de Educación Infantil (promoción 2015/2019) y continuar utilizando el portafolio digital Mahara durante el periodo de prácticas 2017, 2018 y 2019 en centros escolares con el asesoramiento o tutoría de algunas de las docentes de $1 \stackrel{0}{ }$.

- G3: Ser miembro del equipo docente implicado en la coordinación de las tres asignaturas de $1^{\circ}$ de Educación Infantil que hacen uso del portafolio digital Mahara.

- G4: Ser estudiante que ha participado en la experiencia de 1ํ de Educación Infantil en años anteriores al inicio del estudio de casos y tener asignado como tutora de prácticas en centros escolares a alguna de las docentes de primero.

\subsection{Técnicas de recolección}

La recopilación de información se llevó a cabo a través de la observación directa de varias sesiones de clase, un cuestionario abierto inicial, un cuestionario abierto final, entrevistas individuales a las docentes, entrevistas individuales al estudiantado, grupos focales, un cuestionario cerrado final y análisis documental de portafolios. Dado el anonimato y voluntariedad de la participación, la proporción de la muestra varía en función de la herramienta utilizada para la recopilación, tal y como se indica en la Tabla 1. 
Tabla 1

Descripción de los instrumentos de investigación utilizados en el estudiantado y profesorado de la Universidad de Málaga-España, 2016-2018

\begin{tabular}{|c|c|c|c|c|c|c|}
\hline \multicolumn{7}{|c|}{ INSTRUMENTOS DE INVESTIGACIÓN } \\
\hline $\begin{array}{c}\text { Herramienta } \\
\text { utilizada }\end{array}$ & $\begin{array}{c}\text { Características de } \\
\text { la herramienta }\end{array}$ & $\begin{array}{c}\text { Muestra de } \\
\text { participantes }\end{array}$ & $\begin{array}{l}\text { Promoción del } \\
\text { alumnado }\end{array}$ & \multicolumn{2}{|c|}{$\begin{array}{c}\text { Recopilación de } \\
\text { información }\end{array}$} & $\begin{array}{l}\text { Finalidades de } \\
\text { la recopilación }\end{array}$ \\
\hline \multirow[t]{2}{*}{$\begin{array}{c}\text { Diario de } \\
\text { Campo (DC) }\end{array}$} & \multirow{2}{*}{$\begin{array}{l}\text { Observación } \\
\text { externa, no } \\
\text { participante, escrita, } \\
\text { con apoyo puntual } \\
\text { de la fotografía }\end{array}$} & 60 estudiantes (G1) & \multirow{11}{*}{ 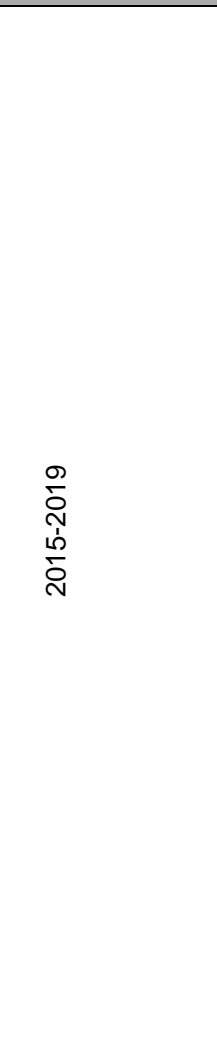 } & \multirow{2}{*}{ 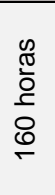 } & \multirow{2}{*}{40 sesiones } & \multirow{2}{*}{$\begin{array}{c}\text { Conocer las } \\
\text { estratégicas } \\
\text { metodológicas de } \\
\text { las sesiones y las } \\
\text { características del } \\
\text { grupo }\end{array}$} \\
\hline & & $\begin{array}{c}4 \text { docentes } \\
\text { (G3: D1...D4) }\end{array}$ & & & & \\
\hline \multirow{2}{*}{$\begin{array}{l}\text { Cuestionarios } \\
\text { abiertos (CA) }\end{array}$} & \multirow{2}{*}{$\begin{array}{l}\text { Voluntario y } \\
\text { anónimo, } \\
\text { conformado por } 12 \\
\text { preguntas de } \\
\text { respuesta libre } \\
\text { sobre el portafolio }\end{array}$} & 29 estudiantes (G1) & & & $\begin{array}{c}\text { Al inicio } \\
22 / 02 / 2016\end{array}$ & \multirow{2}{*}{$\begin{array}{l}\text { Identificar la } \\
\text { predisposición } \\
\text { inicial del } \\
\text { alumnado } \\
\text { y su posterior } \\
\text { evolución }\end{array}$} \\
\hline & & 50 estudiantes (G1) & & & $\begin{array}{c}\text { Al final } \\
06 / 06 / 2016\end{array}$ & \\
\hline $\begin{array}{l}\text { Cuestionarios } \\
\text { Cerrados (CC) }\end{array}$ & $\begin{array}{c}\text { Voluntario y } \\
\text { anónimo, } \\
\text { conformado por } 29 \\
\text { preguntas, utilizando } \\
\text { la escala de Likert }\end{array}$ & 50 estudiantes (G1) & & \multicolumn{2}{|r|}{$\begin{array}{c}\text { Al final } \\
06 / 06 / 2016\end{array}$} & $\begin{array}{c}\text { Apoyar y } \\
\text { complementar el } \\
\text { análisis de los } \\
\text { cuestionarios } \\
\text { abiertos }\end{array}$ \\
\hline $\begin{array}{c}\text { Análisis de } \\
\text { portafolios (AP) }\end{array}$ & $\begin{array}{l}\text { Lectura analítica, } \\
\text { de búsqueda, } \\
\text { comparación y } \\
\text { confrontación }\end{array}$ & $\begin{array}{l}2 \text { estudiantes } \\
\text { (G2: E1 y E2) }\end{array}$ & & \multicolumn{2}{|r|}{$\begin{array}{l}\text { Septiembre } \\
2017\end{array}$} & $\begin{array}{c}\text { Profundizar en el } \\
\text { foco de estudio y } \\
\text { buscar categorías } \\
\text { emergentes }\end{array}$ \\
\hline \multirow{3}{*}{$\begin{array}{c}\text { Entrevistas } \\
\text { individuales a las } \\
\text { docentes (ED) }\end{array}$} & \multirow{3}{*}{$\begin{array}{l}\text { Semiestructuradas, } \\
\text { etnográficas, en } \\
\text { profundidad e } \\
\text { inquisitivas }\end{array}$} & \multirow{3}{*}{$\begin{array}{c}3 \text { docentes } \\
\text { (G3: D1, D2 y D3) }\end{array}$} & & \multirow{3}{*}{$\begin{array}{l}\frac{4}{\pi} \\
\frac{\pi}{0} \\
\frac{\pi}{0}\end{array}$} & $\begin{array}{r}\text { (D1): } \\
21 / 06 / 2016 \\
\end{array}$ & \multirow{3}{*}{$\begin{array}{l}\text { Profundizar en el } \\
\text { foco de estudio y } \\
\text { buscar categorías } \\
\text { emergentes }\end{array}$} \\
\hline & & & & & $\begin{array}{r}\text { (D2): } \\
21 / 07 / 2016\end{array}$ & \\
\hline & & & & & $\begin{array}{r}\text { (D3): } \\
21 / 07 / 2016\end{array}$ & \\
\hline \multirow{2}{*}{$\begin{array}{c}\text { Entrevistas } \\
\text { individuales al } \\
\text { estudiantado (EE) }\end{array}$} & \multirow{2}{*}{$\begin{array}{l}\text { Semiestructuradas, } \\
\text { etnográficas, en } \\
\text { profundidad e } \\
\text { inquisitivas }\end{array}$} & \multirow{2}{*}{$\begin{array}{l}2 \text { estudiantes } \\
\text { (G1: E1 y E2) }\end{array}$} & & \multirow{2}{*}{$\begin{array}{l}\mathbb{N} \\
\frac{\mathbb{T}}{\mathrm{d}} \\
\frac{\mathrm{C}}{N}\end{array}$} & $\begin{array}{r}\text { (E1): } \\
13 / 06 / 2018\end{array}$ & \multirow{2}{*}{$\begin{array}{l}\text { Profundizar en el } \\
\text { foco de estudio y } \\
\text { buscar categorías } \\
\text { emergentes }\end{array}$} \\
\hline & & & & & $\begin{array}{r}\text { (E2): } \\
27 / 06 / 2018\end{array}$ & \\
\hline \multirow{5}{*}{$\begin{array}{l}\text { Grupos focales } \\
\text { (GF) }\end{array}$} & \multirow{5}{*}{$\begin{array}{c}\text { Entrevista } \\
\text { exploratoria grupal } \\
\text { y semiestructurada }\end{array}$} & $\begin{array}{l}8 \text { estudiantes } \\
\text { (G4: A1 ...A8) }\end{array}$ & $2010-2017$ & \multicolumn{2}{|r|}{ Mayo 2016} & \multirow{5}{*}{$\begin{array}{c}\text { Profundizar en el } \\
\text { foco de estudio a } \\
\text { través de las } \\
\text { experiencias de } \\
\text { otros estudiantes } \\
\text { del grado } \\
\end{array}$} \\
\hline & & $A 1, A 2$ y $A 3$ & $2010-2014$ & \multirow{4}{*}{ 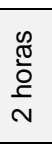 } & \multirow[t]{2}{*}{$18 / 05 / 2016$} & \\
\hline & & A4 & $2011-2015$ & & & \\
\hline & & $A 5$ y $A 6$ & $2012-2016$ & & $25 / 05 / 2016$ & \\
\hline & & A7 y A8 & 2013-2017 & & & \\
\hline
\end{tabular}

Fuente: elaboración propia a partir de los datos de la investigación, 2019.

\subsection{Procesamiento de análisis}

Tratándose de una investigación mixta que combina instrumentos para la recopilación de información de naturaleza fundamentalmente cualitativa con otro de corte cuantitativo, el análisis se desarrolló a través de dos procedimientos distintos. Por un lado, la información cualitativa procedente de las observaciones, entrevistas, lecturas de portafolios, grupos focales y cuestionarios abiertos fue analizada a través del paradigma interpretativo propio del estudio de casos, siguiendo los procedimientos de identificando de variables, establecimiento de valores, categorización de los datos, refinamiento, triangulación e interpretación (Stake, 
2005). Para ello, nos ayudamos del software de análisis de datos cualitativo Nvivo que favorece la codificación, organización y saturación de categorías. Por otro lado, para los cuestionarios cerrados se siguió el método estadístico habitual, a través de un análisis descriptivo de frecuencias y porcentajes cuyos resultados fueron cotejados con los anteriores.

La investigación partió de la búsqueda de determinados intereses focalizados en el uso del portafolio digital, así como sus posibilidades y restricciones pedagógicas. Las ideas previas y lecturas bibliográficas permitieron establecer algunas categorías iniciales que configuraron la base para la recogida de información. No obstante, el análisis de la información a través de rigurosas y continuas comparaciones, hizo emerger nuevos focos temáticos, conduciendo a la reagrupación o recodificación que resultaron en las siguientes categorías finales, tal y como recoge la Tabla 2:

Tabla 2

Categorías iniciales y finales utilizadas en los estudios de casos del estudiantado y profesorado de la Universidad de Málaga-España, 2016-2018

\begin{tabular}{|l|}
\hline \multicolumn{1}{|c|}{ CATEGORIAS INICIALES } \\
\hline Definición personal del portafolio, sus usos y tipologías \\
\hline Experiencias previas con el portafolio y grado de satisfacción \\
\hline Relación entre la metodología y la calidad del portafolio \\
\hline Valoración del portafolio como herramienta de aprendizaje y evaluación \\
\hline Emociones suscitadas por la herramienta \\
\hline Relación entre el portafolio y el autoconocimiento \\
\hline Competencias que la herramienta ayuda a desarrollar \\
\hline El portafolio Mahara como red social \\
\hline Fortalezas y debilidades de la herramienta \\
\hline \multicolumn{1}{|c|}{ CATEGORIAS FINALES } \\
\hline p. Necesidad de generar una definición y estrategia metodológica compartida \\
\hline B. El portafolio educativo favorece la construcción del conocimiento \\
\hline C. El portafolio educativo ayuda a reconstruir el pensamiento práctico \\
\hline D. El portafolio educativo promueve el desarrollo de competencias profesionales \\
\hline E. El portafolio educativo permite llevar a cabo una evaluación integral \\
\hline
\end{tabular}

Fuente: elaboración propia a partir de los datos de la investigación, 2019. 
La validez de la investigación se aseguró por una triple vía: a) la observación prolongada y detallada del aula foco de la investigación; b) múltiples estrategias para la recopilación de información hasta llegar a su saturación; c) la triangulación metodológica y de informantes simultáneos (Rodríguez Gómez, Gil Flores y García Jiménez, 1999) de la información mediante la combinación de datos de carácter cuantitativos y cualitativos, por un lado, y la confrontación de opiniones de diferentes participantes (estudiantes, profesorado y alumnado antiguo) por el otro.

\section{Resultados de la investigación}

A continuación exponemos algunas de las evidencias que configuran las categorías finales. Para ello, utilizaremos la siguiente codificación: (GF.G4 - A1), donde la primera notación corresponde al instrumento de recopilación de información (Tabla 1); la segunda, al grupo de participantes (Figura 3) y la tercera, al integrante concreto (Tabla 1).

\subsection{Necesidad de generar una definición y estrategia metodológica compartida para el uso del portafolio educativo}

En los últimos años, las transformaciones impulsadas por el EEES han favorecido que el uso del portafolio en la universidad "se haya popularizado" (ED.G3 - D2). No obstante, y aunque son cada vez más los profesores y profesoras que se animan a utilizarlo en sus aulas, el manejo y finalidad de la herramienta no siempre son los mismos. Las personas participantes coincidieron al señalar que aún continúan predominando los portafolios "demasiado teóricos y academicistas" (EE.G2 - E2), lo que conduce a propuestas educativas pobres, incompletas o de escasa significación entre el estudiantado:

(ED.G3 - D3) Algunos docentes entienden el portafolio como un cuaderno de bitácora, como una agrupación de elementos muy alejada de su verdadera esencia. Hacen reproducciones que poco sirven para la reconstrucción del pensamiento práctico o la percepción del propio proceso de aprendizaje [...] Es decir, hay una gran diferencia entre lo que se dice en la teoría y lo que se hace en la práctica.

(GF.G4 - A6) Se trata de un barranco en el que puedes caer y convertir el portafolio en algo totalmente instrumental donde se recoge todo y ese es mi portafolio. 
En este sentido, el alumnado protagonista de la investigación, que ya había tenido experiencias previas con el portafolio durante el primer cuatrimestre, mostró una predisposición negativa cuando sus nuevas profesoras presentaron el proyecto de las tres asignaturas y explicaron que utilizarían esta herramienta:

(DC. G1) Algunas alumnas suspiraron y comentaron que no habían tenido buena experiencia con el portafolio. "Preferiría hacer un examen tipo test, antes que el portafolio”. Señaló una. “¿No aprendisteis nada con el portafolio?” Preguntó la profesora. "No lo sabemos, aún no hemos recibido la nota". Respondió la alumna. "Pero, ¿Sentís que habéis aprendido?” Insistió la docente. "Es que hasta que no sepamos si hemos aprobado, no sabremos si hemos aprendido..."

Esta evidencia no solo pone de manifiesto la preocupante desconexión del alumnado con sus propios procesos internos o su excesiva dependencia por la validación externa, sino que además nos permite comprender la necesidad de establecer una definición compartida del término portafolio, especialmente cuando nos referimos al portafolio educativo digital. Esto permitiría, por un lado, evitar un uso y/o manejo inconveniente de la herramienta que poco tiene que ver con la reproducción de estrategias metodológicas tradicionalistas y, por el otro, favorecería la comprensión de su naturaleza introspectiva, metacognitiva, guiada y autoevaluadora de los procesos de enseñanza aprendizaje que propone.

\subsection{El portafolio educativo favorece la construcción del conocimiento}

Las prolongadas observaciones en el aula permitieron descubrir las particularidades del grupo de estudiantes protagonistas del estudio de casos. Podríamos decir que se trataba de un grupo atento y disciplinado, caracterizado, en un principio, por la escasa expresividad ante las propuestas docentes, la falta de participación en los debates, el excesivo academicismo y un trato interpersonal distante. En repetidas ocasiones, el alumnado reconoció que esa inacción o aparente apatía era producto de sus propias experiencias escolares, en la que los conocimientos siempre les habían sido transmitidos sin la necesidad de esfuerzos o colaboración por su parte. En este sentido, solicitaban comprensión ante sus inseguridades para hablar, opinar u hacer sugerencias en público: 
(DC.G1) “¿Por qué tenéis miedo de levantar la mano? ¿A qué se debe?" Preguntó la profesora. Un par de alumnas se animaron a responder. "Por miedo a equivocarnos y hacer el ridículo" Respondió una. "Yo creo que es por el tipo de escuela que hemos tenido, en la que nuestra voz no cuenta. Nos enseñan a eso". Señaló otra (15/02/16)

Sin embargo, las propuestas metodológicas y el uso del portafolio digital empujaban al alumnado a abandonar su zona de confort. Ya no eran sujetos pasivos, sino protagonistas de su propio aprendizaje. En un principio, estos cambios provocaron "miedo e incertidumbre" (CC.G1), sentimientos compartidos con estudiantes de otras promociones que también habían vivido la experiencia:

(GF.G4 - A1) ¿Que qué sentía hacía el portafolio? Al principio estrés, agobio, miedo ¿Esto para qué es?

(GF.G4 - A3) Nos costaba ponernos a reflexionar, veníamos de bachillerato.

(GF.G4 - A2) Yo lo que me di cuenta es que yo no sabía pensar. Yo me quedaba en plan $<<$ ¿Y ahora qué escribo?>>

No obstante, a medida que el tiempo pasaba y los hábitos se iban consolidando, las personas participantes comenzaban a reconocer y valorar el potencial de la herramienta para "construir y estructurar sus conocimientos" (GF.G4 - A7):

(GF.G4 -A8) gracias al portafolio puedes indagar, puedes investigar, puedes ser creativo y eso lo considero muy importante.

(EE.G2 - E1) tu construyes tus conocimientos [...] por ejemplo, en un examen se les pide los mismos conocimientos a todas las personas, que los memorizan [...] Entonces, todo el mundo tiene que saber lo mismo. Algunos lo sabrán, incluso, con las mismas palabras. Sin embargo, en el portafolio cada persona construye aprendizajes diferentes, pero seguimos teniendo aprendizajes. Aprendemos, aunque sean cosas diferentes.

\subsection{El portafolio educativo promueve el desarrollo de competencias profesionales}

El uso continuado del portafolio educativo parece favorecer el desarrollo de buena parte de las competencias profesionales indispensables en el ejercicio docente (apartado 2.3), que puede traducirse como pensamiento reflexivo o capacidad de abordar diversas temáticas conjugando los propios conceptos con otros involucrados, la búsqueda de 
información, la creatividad y el pensamiento crítico o capacidad para fundamentar lo que se presenta, así como cuestionar las afirmaciones que no ofrecen explicación (GF.G4 - A4, A7 y A8). A todo ello se suma, además, el desarrollo de la autonomía, la expresión escrita, el trabajo en equipo y la competencia en el manejo de las nuevas tecnologías (ED.G3).

La Tabla 3 recoge el número de alusiones a las competencias que el alumnado considera que el portafolio les ayuda a desarrollar, como la responsabilidad, el pensamiento crítico y la autonomía. La primera de ellas tiene un importante incremento de alusiones en el cuestionario final, donde además aparecen nuevos ejes, como la importancia del portafolio para aprender a aplicar los conocimientos de una manera práctica y creativa a través de las nuevas tecnologías.

Tabla 3

Número y porcentaje de alusiones del alumnado sobre las competencias que el portafolio desarrolla, seqún tipo de cuestionario (inicial v final), Universidad Málaqa-España, 2016

Cuestionario abierto

P7. ENUMERA LAS COMPETENCIAS QUE CONSIDERAS QUE EL PORTAFOLIO TE AYUDA A DESARROLLAR

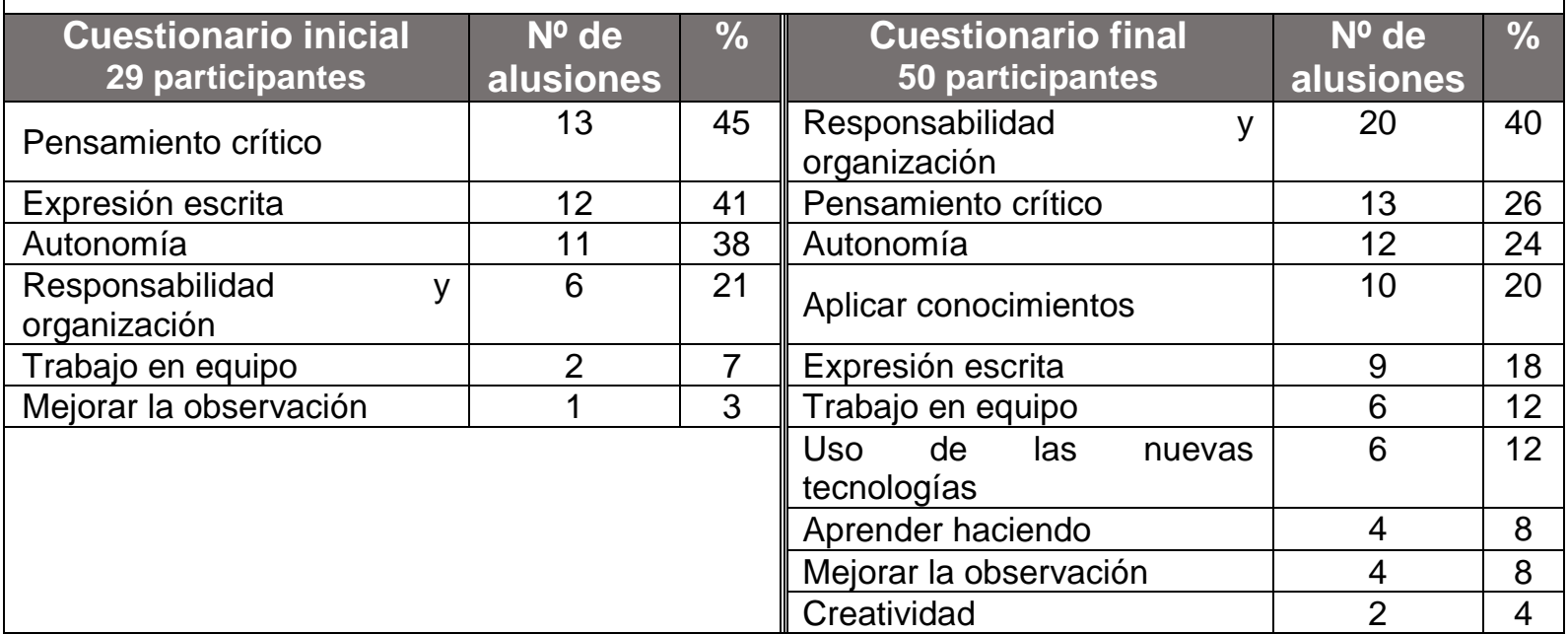

Fuente: elaboración propia a partir de los datos de la investigación, 2019.

\subsection{El portafolio educativo ayuda a reconstruir el pensamiento práctico}

El pensamiento práctico es aquel conocimiento consciente en la acción y sobre la acción que incluye los procesos de reflexión para generar nuevas respuestas. Gracias a las experiencias vividas y al uso del portafolio, los participantes señalaron que se les "rompieron los esquemas" (EE.G2 - E1) que formaban parte de sus conocimientos inconscientes, ayudándoles a "ver los fallos, madurar y aprender cosas de sí mismos" (EE.G2 - E2).

"Yo siempre había pensado que la enseñanza en un centro debía ser con todos los alumnos y alumnas sentados/as en sus mesas, trabajando una ficha, todos al mismo 
tiempo, con el mismo tiempo para acabar la tarea que se les ha mandado y sin pensar si realmente les apetecía o no hacerla. Al poder trabajar ese concepto mediante dinámicas y feedbacks con todas mis compañeras pude darme cuenta de lo equivocada que estaba. Ahora sé que cada persona tiene su propio ritmo para hacer las cosas y que forzar a todo el mundo a ir a la misma marcha solo agobia a los/las que necesitan más tiempo y aburre al que termina rápido. Si la educación se trata de desarrollar las competencias establecidas en el currículum, está claro que hay que tener en cuenta los diferentes ritmos de aprendizaje" (AP.G2 - E2, Junio 2016).

Asimismo, los participantes de otras promociones aseguraron continuar sacando partido de los procesos internos que habían reflejado en su portafolio.

(GF.G4 - A2): La cosa es que continúo dándome cuenta de algunas cosas. Yo me sigo metiendo en mi Portafolio Mahara y digo <<Qué mal escribía...>> Lo primero es eso y luego me cuestiono muchas cosas « ¿Yo por qué pensaba esto? ¡Cómo he cambiado!>>

(GF.G4 - A7): A mí me ha ayudado a cambiar. Yo como persona he cambiado. Yo, por ejemplo, este año fui a las prácticas y me di cuenta que lo que escribía en el portafolio era una cosa y lo que hacía una totalmente diferente y me di cuenta al leer lo que había escrito.

Sin embargo, las profesoras señalaron que este proceso podría fortalecerse si el uso del portafolio fuese continuado a lo largo de toda la formación docente, ya que la accesibilidad y continuidad de la herramienta durante todo el plan de estudios, fundamentalmente a través de las diferentes prácticas en los centros, hace que se convierta en algo suyo, un espejo al que volver a mirarse y en el que a veces el alumnado no se reconoce.

(ED.G3 - D1): La mayor parte de estudiantes profundiza en la reflexión a lo largo del cuatrimestre, sin embargo, en este breve espacio de tiempo es difícil percibir la reconstrucción del pensamiento práctico. Yo creo que algo sí que se reconstruye, gracias a la parte de reflexión que tiene el portafolio. Van deconstruyendo a medida que perciben cómo su idea de escuela se desmorona. Pero para lograr una reconstrucción del pensamiento práctico definitiva haría falta que este proceso continuara en el tiempo. Es decir, que luego, en segundo, tuvieran otras asignaturas donde se trabajara con 
principios pedagógicos parecidos. De este modo, podrían seguir deconstruyendo y construyendo durante los cuatro años de carrera.

\subsection{El portafolio educativo permite llevar a cabo una evaluación integral}

Las personas participantes debatieron sobre la objetividad y subjetividad de los procesos de evaluación, llegando a la conclusión de que la aparente subjetividad del portafolio era más justa y razonable que la imparcial objetividad de un examen, y que sobre todo ayudaba a entender la evaluación como un proceso de mejora y aprendizaje con ellos como protagonistas, no como sanción o calificación final.

Tabla 4

Número de estudiantes por el tipo de uso que permitió el portafolio al final del periodo académico según frecuencia de uso, Universidad Málaga-España, 2016

\begin{tabular}{|l|c|c|c|c|}
\hline \multicolumn{1}{|c}{ EL USO DEL PORTAFOLIO ME PERMITE } & \multicolumn{2}{c|}{ NADA } & POCO & \multicolumn{2}{c|}{ ALGO } & MUCHO \\
\hline XV. Ser consciente de mi propio aprendizaje & 1 & 4 & 23 & 22 \\
\hline XVI. Percatarme de mi evolución & 2 & 19 & 18 & 11 \\
\hline XVII. Establecer una relación más positiva con el docente & 4 & 8 & 20 & 18 \\
\hline XVIII. Sentirme escuchado y valorado & 2 & 3 & 16 & 29 \\
\hline XIX. Ser capaz de autoevaluarme & 23 \\
\hline
\end{tabular}

Fuente: elaboración propia a partir de los datos de la investigación, 2019.

(GF.G4 - A1): Cuando tú le pones un examen a una persona, tú no ves lo que a esa persona se le ha pasado por la cabeza. Solamente ves una cosa que puede haberse aprendido de memoria, pero no sabes hasta qué punto lo ha podido interiorizar [...] entonces, un examen no es justo, vale, me pones un siete, pero ¿Por qué? Explícamelo. Explícame qué significado tiene ese siete. En el portafolio, en cambio, te dejan comentarios que permiten que te des cuenta de si vas bien y cómo mejorar. Y lo más importante, tienes esa opción de poder mejorar.

GF.G4 - A3): Además, el examen es solo final, en una hora determinada, aunque te encuentres mal. En cambio, en el portafolio está todo el proceso y puedes autoevaluarte. (EE.G2 - E2): Te ven desde otro plano diferente al de, simplemente, una persona que está en clase y levanta la mano [...] pueden tener muchas más cosas en cuenta.

(GF.G4 - A7) El portafolio refleja el verdadero aprendizaje de una persona. Creo que por eso es más justo que un examen que no puede tener en cuenta lo que una persona ha trabajado [...] Es justa y al mismo tiempo, subjetiva. 
GF.G4 - A6) Pero es que si la evaluación fuese objetiva no tendría sentido. Es que, además, yo creo que tiene que ser subjetiva, porque somos sujetos y no podemos medir ciertas cosas de otra forma. Dos personas pueden llegar a la misma conclusión, pero a lo largo de diferentes procesos. Entonces ¿El cómo? ¿No se tiene en cuenta?

Estos procesos también se reflejaron en el cuestionario cerrado (Tabla 4), donde el alumnado valoró positivamente las virtualidades del portafolio en la evaluación.

Asimismo, el equipo docente, se mostró afín con esta manera de entender la evaluación, desde su potencial educativo y de mejora constante.

(ED.G3 - D2): La principal fortaleza del portafolio es una evaluación que en realidad es un elemento de aprendizaje, que le permite a cada estudiante ir dándose cuenta de cuáles son sus procesos e ir poniéndose desafíos y retos para mejorar [...] En definitiva, es un instrumento para la autorregulación que es el propósito de la evaluación, entendida como darse cuenta de cuáles son las limitaciones y los obstáculos que cada uno tiene y de su mejora permanente.

\section{Conclusión}

Los resultados de esta investigación pueden ayudarnos a comprender cuál es la predisposición inicial y posterior evolución del alumnado de la Universidad de Málaga cuando se inicia, durante su primer año, en el uso del portafolio educativo digital Mahara, una herramienta de enseñanza, aprendizaje y evaluación que busca promover procesos intelectuales de orden superior. Aunque se han llevado a cabo investigaciones similares en torno a la herramienta y su funcionalidad durante las prácticas docentes en centros, como la que tuvo lugar en la Universidad de Granada, que encontró que favorecía la formación de docentes reflexivos, capaces de vincular la teoría con la práctica en un proceso continuo de reconstrucción del conocimiento práctico (Romero López, Ibáñez Cubillas y Gámiz Sánchez, 2017), el estudio de su aplicación como herramienta de aprendizaje y evaluación en varias asignaturas que trabajan interdisciplinarmente y durante el primer año de ingreso, parece novedoso.

En este sentido, la investigación, también nos permite conocer de qué modo las experiencias previas en la escuela, predominantemente tradicional, condiciona el desarrollo competencial del alumnado y cómo las nuevas estrategias metodológicas utilizadas durante 
la formación inicial docente pueden ayudar a modificar los modelos educativos arcaicos y favorecer las necesidades formativas de los ciudadanos y ciudadanas del siglo XXI.

Por un lado, el estudio nos muestra un grupo de estudiantes universitarios poco participativo, con serias dificultades para hablar en público, trabajar en equipo o reflexionar, muy habituado y cómodo con su rol pasivo, propio de la metodología tradicional de etapas anteriores. Estas condiciones, unidas a un uso previo y superfluo de la herramienta portafolio, comportaron un inicio de curso difícil, invadido de miedos e inseguridades, especialmente hacia la evaluación. La investigación también nos advierte cómo, desde el principio, hubo estudiantes motivados por los cambios que se anunciaban, pero también eran usuales las quejas asociadas al carácter continuo y formativo de los procesos de enseñanza, aprendizaje y evaluación, a los que no se encontraban habituados.

El seguimiento de la experiencia y el análisis de la información recopilada reflejan que los participantes tuvieron dificultades para adaptarse. El paso de un rol pasivo a otro activo, en el que el trabajo reflexivo y la reelaboración de conceptos eran continuos, no fue sencillo. Incluso aquellos que encontraban la herramienta y métodos enriquecedores, no escatimaban en compartir las emociones negativas que experimentaban. Hay que recordar que esta experiencia se desarrolla en primero de carrera, cuando el alumnado ingresa a la Universidad, tras bachillerato. No obstante, a pesar de las dificultades, centradas especialmente en el esfuerzo requerido e inseguridades hacia la evaluación, el alumnado valoró positivamente su evolución y progreso a lo largo del curso, confesando que volvería a escoger el portafolio educativo sobre cualquier otra herramienta de aprendizaje y evaluación si se les diese la oportunidad.

Asimismo, los resultados nos permiten conocer algunas virtualidades pedagógicas del portafolio digital Mahara como herramienta de enseñanza, aprendizaje y evaluación que pueden ayudarnos a confrontar los retos educativos del siglo XXI, como su potencial para favorecer la construcción del propio conocimiento, la reconstrucción del pensamiento práctico, la formación en competencia o la evaluación integral. Todo ello, siempre y cuando se haga un uso prolongado de la herramienta y se trabaje a través de una metodología constructivista.

Así pues, la plasticidad y posibilidades del portafolio digital Mahara para efectuar cambios estructurales y de contenidos parecen favorecer la flexibilización del pensamiento y la adaptación a esa falta de certezas o determinismos, característica de nuestros tiempos. Asimismo, promueve el desarrollo del pensamiento reflexivo, la argumentación consistente y 
el espíritu crítico, competencias necesarias para sobrellevar la sobrecarga informativa a la que hacemos frente todos los días. El portafolio también estimula la valoración de las experiencias de aprendizaje personales por encima de los objetos más tangibles, invitándonos a cuestionar el hiperconsumismo circundante y a valorar la calidad por sobre la cantidad. Del mismo modo, promueve los procesos a largo plazo, en contraposición a los resultados inmediatos propios de la hiperproductividad. Se trata, además, de una herramienta que parece ayudar a desarrollar la paciencia, necesaria para hacer una pausa, reflexionar a través de la escritura, evaluar los procesos de enseñanza aprendizaje y valorar la evolución. Al mismo tiempo, nos introduce de una manera crítica en la construcción de la propia identidad digital, a través de la elaboración de una biografía de vida y la decisión consciente sobre aquello en lo que queremos convertirnos o aspiramos ser.

En conclusión, podríamos decir que el portafolio digital Mahara es una herramienta congruente con las nuevas demandas educativas del siglo XXI en tanto y cuanto se adapta a los principios defendidos por la EEES y favorece el desarrollo de las competencias necesarias para afrontar los nuevos retos sociales y formar al profesorado que educará a los niños y niñas. Esta investigación también invita a profundizar en el estudio sobre las buenas prácticas de evaluación cualitativa en la universidad, la actualización tecnológica en el ámbito educativo, así como las estrategias de enseñanza aprendizaje para promover el desarrollo de competencias y conocimiento práctico de los futuros y futuras docentes.

\section{Referencias}

Armitage, John. (2001). From modernist to hypermodernist and beyond. En John Armitage (Ed.), Virilio Live: Selected interviews (pp. 15-51). Londres, Inglaterra: Sage.

Barragán Sánchez, Raquel. (2005): El Portafolios, metodología de evaluación y aprendizaje de cara al nuevo Espacio Europeo de Educación Superior. Una experiencia práctica en la Universidad de Sevilla. Revista Latinoamericana de Tecnología Educativa 4(1), 121139.

Bauman, Zygmunt. (2004). Modernidad líquida. México: Editorial Fondo de Cultura Económica.

Bauman, Zygmunt. (2007). Los retos de la educación en la modernidad líquida. Barcelona. España: Gedisa Editorial.

Beriain, Josetxo. (2005). Modernidades en disputa. Barcelona, España: Anthropos Editorial.

Buxarrais, María Rosa. (2003). Los valores de una sociedad individualista y consumista. Revista de la Confederación Española de Padres y Madres de Alumnos, (76), 7-14 
Cano, Elena. (2005). El portafolios del profesorado universitario. Un instrumento para la evalua-ción y para el desarrollo profesional. Barcelona, España: Octaedro.

Calderhead, James. y Shorrock, Susan (1997). Understanding Teacher Education. Londres, Inglaterra: The Falmer Press.

Castro Quitora, Lucila. (2006). El uso del portafolio de aprendizaje como herramienta innovadora en los procesos de la evaluación. Recuperado de https://bit.ly/2JdrTkG

Cornellá, Alfons. (2004). Infoxicación: buscando un orden en la información. Barcelona, España: Zero Factory S.L.

Creswell, John. y Plano, Vicki. (2011). Designing and Conducing Mixed Methods Research. California, Estados Unidos: Sage Publications.

Danielson, Charlotte. y Abrutyn, Leslye. (1999). Una introducción al uso de portafolios en el aula. México: Fondo de Cultura Económica [PDF]. Recuperado de https://bit.ly/2CPaKZn

Daza, Humberto. (2010). La sociedad moderna. Revista Venezolana de Economía y Ciencias Sociales, 16(2), 61-83 Recuperado de https://bit.ly/2u9ctaR

De Kunder, Maurice. (15 de noviembre de 2018). The size of the World Wide Web [Sitio web]. Holanda. Recuperado de http://www.worldwidewebsize.com

García-Galera, Mari Carmen. y Valdivia, Angharad. (2014). Prosumidores mediáticos. Cultura participativa de las audiencias y responsabilidad de los medios. Comunicar, 43(22), 10 13. doi: http://dx.doi.org/10.3916/C43-2014-a2

Giné Freixes, Núria. (2009). Cómo mejorar la docencia universitaria: el punto de vista del estudiantado. Revista Complutense de Educación, 20(1), 117-134. Recuperado de https://bit.ly/2Kdivkx

Giones Valls, Aina y Serrat Brustenga, Marta. (2010). La gestión de la identidad digital: una nueva habilidad informacional y digital. BiD: textos universitaris de biblioteconomia $i$ documentació, 24. Recuperado de https://bit.ly/1pNin8E

Goñi Zubieta, Carlos. (2010). Ética borrosa. Sobre la necesidad de la reflexión y el silencio. Madrid, España: Ediciones Palabra S.A.

Imbernón Muñoz, Francisco. (2017). Ser docente en una sociedad compleja: la difícil tarea de enseñar. Barcelona, España: Editorial Graó.

Junta de Andalucía. (2009). Aprender en la Universidad. El sentido del cambio en el EEES. Madrid, España: Ediciones Akal, S.L.

Klenowski, Val. (2014). Desarrollo del portafolio para el Aprendizaje y la Evaluación. Procesos y Principios. Madrid, España: Narcea S.A. Ediciones.

Lipovetsky, Gilles. (2007). La felicidad paradójica. Ensayo sobre la sociedad del hiperconsumo. Barcelona, España: Editorial Anagrama. 
López Escudero, Ana. (2002). Los expertos relacionan la falta de estrategias de aprendizajes y el fracaso. El País. Recuperado de: https://bit.ly/2UuAMuR

Lyman, Peter., Varian, Hal., Swearingen, Kirsten., Charles, Peter., Good, Nathan., Jordan, Laheem. y Pal, Joyojeet. (2003). How much information? UC Berkeley [Sitio web]. Recuperado de: https://bit.ly/1eeRISA

Lyons, Nona. (Comp.) (2003). El uso de portafolios. Propuestas para un nuevo profesionalismo docente. Buenos Aires, Argentina: Amorrortu editores S.A.

Manzanero Jiménez, Lorena y Pérez García-Ferrería, Javier. (2015). Sobre el derecho al olvido digital: una solución al conflicto entre la libertad de información y el derecho de protección de datos personales en los motores de búsqueda. RJUAM, 32(2), 249-258. Recuperado de https://bit.ly/2SW3kLV

Martínez Segura, María José. (2009). El portafolio para el aprendizaje y la evaluación: utilización en el contexto universitario [PDF]. Murcia, España: Universidad de Murcia. Recuperado de https://bit.ly/2UB66YZ

Martínez, Óscar. (1997). ¿Fin del trabajo o presencia asfixiante del trabajo? Cuentas Pendientes, 1(4). Recuperado de https://bit.ly/2J4hHhN

Moret, Roman. (2012). La postmodernidad: intento de aproximación desde la historia del pensamiento. Bajo palabra, 7, 339-348. Recuperado de https://bit.ly/2HeyEEh

Niño González, José Ignacio., Barquero Cabrero, Mario. y García García, Enrique. (2017). Opinión pública e infoxicación en las redes sociales: los fundamentales de la postverdad. Vivat Academia. Revista de comunicación, (139), 83-94. doi: 10.15178/va.2017.139.83-94

Pérez Gómez, Ángel Ignacio. (2012). Educarse en la era digital. Madrid, España: Ediciones Morata S.L.

Pérez Gómez, Ángel Ignacio (Dir.). (2016). El Portafolio Educativo en Educación Superior. Madrid, España: Ediciones Akal S.A.

Pérez Gómez, Ángel Ignacio. (2017). Pedagogías para tiempos de perplejidad. De la información a la sabiduría. Buenos Aires, Argentina: Editorial Homosapiens.

Pinilla, Rafael. (2017). Tras los duros trabajos: terapias para el nuevo milenio. Artnodes, (19), 21-27. Recuperado de https://bit.ly/2CfwaS3

Pinto Santos, Alba, Díaz Carreño, Jarold, y Santos Pinto, Yorly Andrea. (2018). Infoxicación y capacidad de filtrado: Desafíos en el desarrollo de competencias digitales. Revista científica electrónica de educación y comunicación en la sociedad del conocimiento, 18(1), 102-117. Recuperado de https://bit.ly/2J45SIn

Pozo Municio, Juan Ignacio. (2014). Psicología del Aprendizaje Humano: Adquisición de conocimiento y cambio personal. Madrid, España: Morata. 
Rivera Piragauta, José Alberto. y Minelli de Oliveira, Janaina. (2017). El problema ético de la identidad digital en la educación virtual. Revista Iberoamericana de Educación, 75(2), 41-58. Recuperado de https://bit.ly/2CavilC

Rodríguez Cano, César Augusto. (2017). Los usuarios en su laberinto: burbujas de filtro, cámaras de eco y medición algorítmica en la opinión pública en línea. Virtualis, 8(16), 57-76. Recuperado de https://bit.ly/2Ce4jlb

Rodríguez Gómez, Gregorio., Gil Flores, Javier. y García Jiménez, Eduardo. (1999). Metodología de la investigación cualitativa. Granada, España: Aljibe.

Romero López, Maa Asunción, Ibáñez-Cubillas, Pilar y Gámiz Sánchez, Vanesa. (2017). Diseño de un portafolio digital para la supervisión del prácticum del grado de maestro de educación primaria en la universidad de Granada. En Agustín Erkizia. XIV Symposium Internacional sobre el Prácticum y las Prácticas Externas: "Recursos para un prácticum de calidad". Asociación para el Desarrollo del Prácticum y de las Prácticas Externas: Red de Prácticum (REPPE). Monasterio de Poio. Pontevedra, España.

Shi, David (1985). The Simple Life: Plain Living and High Thinking in American Culture. New York, Estados Unidos: Oxford University Press.

Singly, Fraçois. (2003). Les uns avec les autres. Quand l'individualisme crée un lien, París, Francia: Armand Colin.

Soto Gómez, Encarnación., Barquín Ruíz, Javier. y Fernández Navas, Manuel. (2016). Portafolio electrónico y educativo. En Ángel Ignacio, Pérez (Ed.), El portafolio educativo en educación superior (pp. 135-156). Madrid, España: Ediciones Akal.

Soto Gómez, Encarnación., Serván Nuñez, María José. y Caparrós Vida, Rosa. (2016). Learning to teach with Lesson Study. The practicum and the degree essay as the scenario for reflective and cooperative creation. International Journal for Lesson and Learning Studies, 5(2), 116-129

Stake, Robert. (2005). Investigación con estudio de casos. Madrid, España: Ediciones Morata.

Strauss, Anselm. y Corbin, Juliet. (2002). Bases de la investigación cualitativa. Técnicas y procedimientos para desarrollar la teoría fundamentada. Colombia: Editorial Universidad de Antioquía.

Turkle, Sherry. (2015). Reclaiming Conversation. The Power of Talk in a Digital Age. Nueva York, Estados Unidos: Penguin Press

Uprimny, Rodrigo. (2017). El modelo económico de la pereza. Revista Divergencia, 22, 4972. Recuperado de https://bit.ly/2TlawQu

Valdez Zepeda, Andrés. (2008). No quiero ser competitivo: una crítica a la nueva obsesión de la modernidad. Revista de Investigación en Ciencias de la Administración, 3(4), 99111. Recuperado de https://bit.ly/2NWuBgH 


\section{ANEXO 1: Cuestionario abierto inicial}

\section{ANEXOS}

1. ¿Cómo definirías el portafolio?

2. ¿Has utilizado diferentes tipos de portafolio a lo largo de tu formación? ¿En qué se diferenciaban unos de otros? Explica qué contenidos debías incluir en cada uno de los casos.

3. ¿Cómo afectaba el portafolio a la evaluación de la asignatura en cada una de las experiencias mencionadas?

4. ¿Qué emociones, tanto positivas como negativas, te suscita el trabajo con portafolio? Distingue las emociones provocadas por unas experiencias y por otras ya que pueden no ser las mismas.

5. ¿Qué es lo que más te gusta de trabajar con portafolio en cada uno de las experiencias? ¿Y lo que menos? Diferencia lo que más y lo que menos te gustaba de cada experiencia con portafolios, ya que no tienen por qué coincidir.

6. ¿Crees que el portafolio te ayuda a mejorar profesionalmente? ¿Cuál de los tipos de portafolio mencionados te ayuda a hacerlo mejor? ¿Por qué?

7. Enumera las competencias que consideras que te ha ayudado a desarrollar $\mathrm{el} / \mathrm{los}$ portafolio/s mencionados. Has varias listas si las competencias desarrolladas fueron distintas en cada caso.

8. Nombra las competencias que consideras que el uso del portafolio limita o dificulta.

9. ¿Qué ventajas, virtudes o potencialidades encuentras en el uso de esta herramienta? ¿Crees que existen diferencias según el tipo de portafolio?

10. ¿Qué desventajas, dificultades o inconvenientes destacarías?

11. Si te diesen la oportunidad ¿Escogerías el portafolio cómo herramienta de evaluación durante tu formación? ¿Qué tipo de portafolio preferirías? Si prefieres que te evalúen con otra herramienta ¿Cuál escogerías? ¿Por qué?

12. ¿Te gustaría comentar algo sobre el Portafolios que no te haya preguntado? Puedes hacerlo ahora.

\section{ANEXO 2: Cuestionario abierto final}

1. ¿Cómo definirías el portafolio? ¿y el portafolio digital?

2. ¿Qué emociones, tanto positivas como negativas, te ha suscitado el trabajo con el portafolio digital?

3. ¿Crees que el portafolio digital te ayuda a mejorar profesionalmente? ¿Cuál de los tipos de portafolio con los que has tenido experiencia consideras que te ha ayuda a hacerlo mejor? ¿Por qué?

4. Enumera las competencias que consideras que te ha ayudado a desarrollar el portafolio digital

5. Enumera las competencias que consideras que el uso del portafolio limita o dificulta.

6. ¿Qué ventajas, virtudes o potencialidades encuentras en el uso del portafolio digital?

7. ¿Qué desventajas, dificultades o inconvenientes destacarias?

8. ¿Ha cambiado tu percepción del portafolio a lo largo de este cuatrimestre? ¿en qué sentido?

9. Si te diesen la oportunidad ¿Escogerías el portafolio cómo herramienta de evaluación durante tu formación? ¿Qué tipo de portafolio preferirías? Si prefieres que te evalúen con otra herramienta ¿Cuál escogerías? ¿Por qué?

10. ¿Te gustaría comentar algo sobre el Portafolios que no te haya preguntado? Puedes hacerlo ahora.

\section{ANEXO 3: Entrevista s emi-estructurada al profesorado. Temas a cubrir y orden.}

\footnotetext{
1. Historia y razones para la implementación del portafolio digital en la asignatura

Apoyos y dificultades encontradas

3. Modo de uso y/o experiencia: metodología, objetivos, competencias, evaluación...

4. Valoración del portafolio como herramienta de aprendizaje y evaluación

5. Competencias que se pretenden desarrollar en el alumnado y las que llegan a desarrollarse

6. Funcionalidad del portafolio digital como red social e implicaciones en el desarrollo de la competencia digital

7. Ventajas y desventajas de su uso para el profesorado

8. Nivel de satisfacción de su uso en el profesorado y el alumnado

9. Potencialidades y limitaciones de la herramienta

10. Algo más que decir sobre el portafolio digital o la experiencia
}

\section{ANEXO 4: Entrevista semi-estructurada al alumnado. Temas a cubrir y orden}

\footnotetext{
1. Experiencias con distintos tipos de portafolio. Diferencias y semejanzas

2. Definición, uso y percepción personal del portafolio digital Mahara

3. Experiencia con el portafolio digital Mahara: uso, contenidos, metodología asociada...

4. Emociones suscitadas por la herramienta al principio, durante y al final de la experiencia

5. Nivel de satisfacción general de la herramienta

6. Valoración del portafolio digital como herramienta de aprendizaje, evaluación y red social

7. Influencia del portafolio digital en el establecimiento de relaciones sociales

8. Competencias que consideras haber desarrollado gracias al uso del portafolio digital

9. Ventajas y desventajas de su uso

10. Potencialidades y limitaciones de la herramienta

11. Cambio de perspectiva del portafolio digital tras su uso

12. Algo más que aportar sobre el portafolio digital o la experiencia
} 


\section{ANEXO 5: Grupo focal. Temas a cubrir}

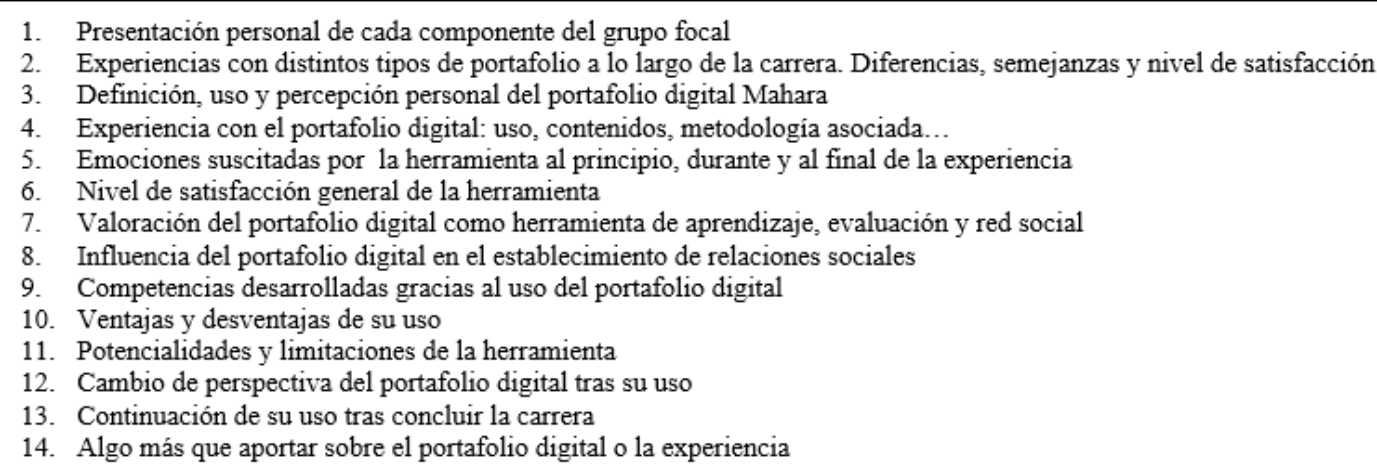

ANEXO 6: Cuestionario cerrado final

\begin{tabular}{|l|c|c|c|c|}
\hline \multicolumn{1}{|c|}{ El uso del portafolio me permite... } & $\begin{array}{c}1 \\
\text { Nada }\end{array}$ & $\begin{array}{c}2 \\
\text { Poco }\end{array}$ & $\begin{array}{c}3 \\
\text { Algo }\end{array}$ & $\begin{array}{c}4 \\
\text { Mucho }\end{array}$ \\
\hline $\begin{array}{l}\text { Gestionar y asentar los conocimientos adquiridos en las } \\
\text { áreas en las cuales se desarrolla. }\end{array}$ & & & & \\
\hline Establecer vínculos entre la teoría y la práctica. & & & & \\
\hline $\begin{array}{l}\text { Desarrollar habilidades en la búsqueda, tratamiento, } \\
\text { valoración y asimilación de la información. }\end{array}$ & & & & \\
\hline Demostrar los conocimientos que he ido adquiriendo. & & & & \\
\hline Construir mi propio conocimiento. & & & & \\
\hline Mejorar mi capacidad reflexiva. & & & & \\
\hline Desarrollar mi espíritu crítico. & & & & \\
\hline Aumentar mi compromiso y autodisciplina. & & & & \\
\hline Ser más autónomo. & & & & \\
\hline Estar motivado. & & & & \\
\hline Aprender a argumentar mis opiniones y puntos de vista. & & & & \\
\hline Conocerme a mí mismo (fortalezas y debilidades). & & & & \\
\hline Comprender a los demás. & & & & \\
\hline $\begin{array}{l}\text { Plasmar con acierto mis inquietudes, pensamientos, } \\
\text { emociones e ideas. }\end{array}$ & & & & \\
\hline Ser consciente de mi propio aprendizaje. & & & & \\
\hline Percatarme de mi evolución. & & & & \\
\hline Establecer una relación más positiva con el docente. & & & & \\
\hline Sentirme escuchado y valorado. & & & & \\
\hline Ser capaz de autoevaluarme & & & 3 & 4 \\
\hline \multicolumn{1}{|c|}{ El uso del portafolio hace que... } & Nada & Poco & Algo & Mucho \\
\hline La tarea me resulte pesada, tediosa y poco motivadora. & & & & \\
\hline Pierda mucho tiempo inútilmente. & & & & \\
\hline Tenga dificultades para plasmar mis reflexiones. & & & & \\
\hline Sienta angustia y desorientación en su elaboración. & & & & \\
\hline Sienta inseguridad hacia la evaluación. & & & & \\
\hline Desconfíe del docente. & & & & \\
\hline Dude de la calidad de mi aprendizaje. & & & & \\
\hline $\begin{array}{l}\text { Me preocupe por la extensión y cantidad de material que } \\
\text { comparto más que de su calidad. }\end{array}$ & & & & \\
\hline $\begin{array}{l}\text { Haga comparaciones entre mi portafolio y el de mis } \\
\text { compañeros por miedo a estar haciéndolo mal. }\end{array}$ & & & & \\
\hline Exprese lo que creo que el docente quiere escuchar. & & & & \\
\hline
\end{tabular}


Revista indizada en
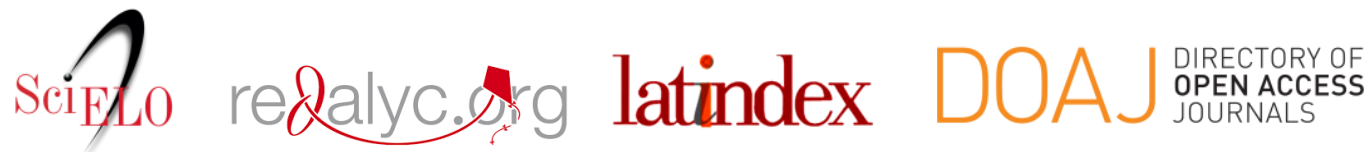

Distribuida en las bases de datos:

- Dialnet

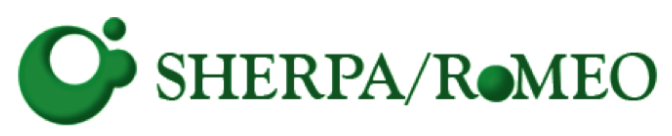

REDIB

Red Iberoamericana

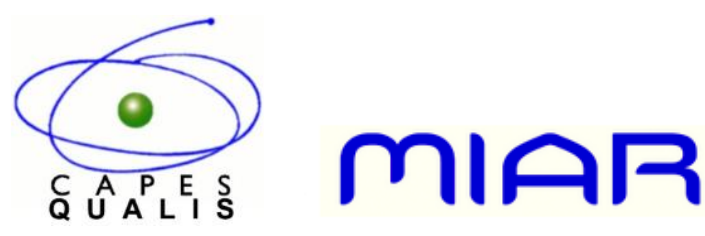

